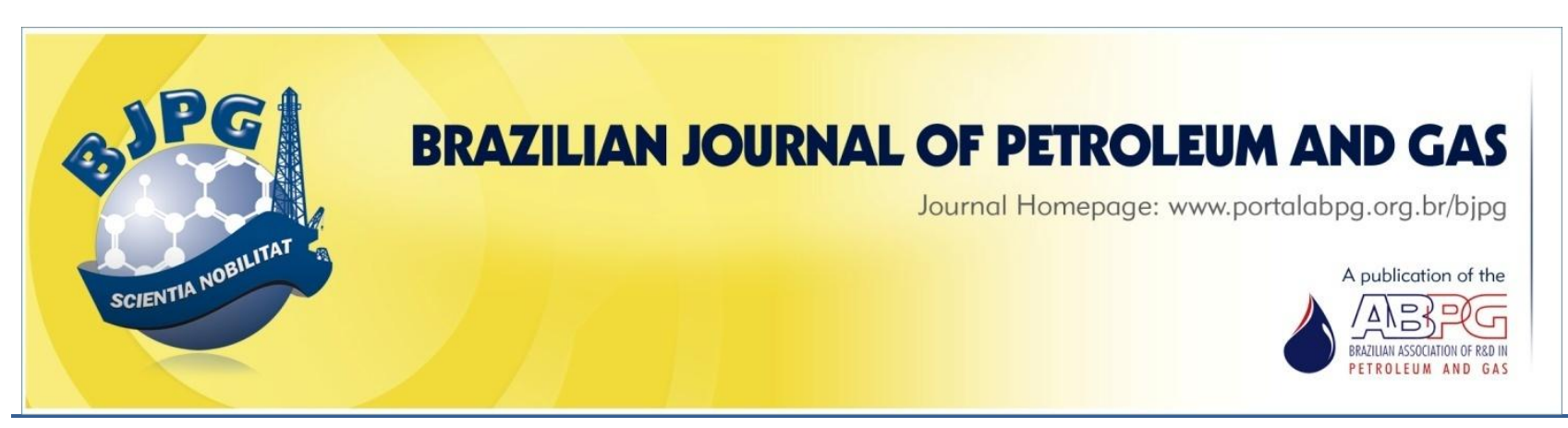

\title{
ANALYZING CHEMICAL REACTION MODELS FOR IN SITU COMBUSTION PROCESS
}

\author{
${ }^{\text {a }}$ Tarifa, J. M. ${ }^{1}$; ${ }^{\text {R }}$ Ruiz, C. P. A.; ${ }^{\text {a }}$ Barillas, J. L. M. \\ a Laboratório de Estudos Avançados de Petróleo - LEAP, Universidade Federal do Rio Grande do Norte - UFRN \\ Received: 14.03.2016 / Revised: 01.06.2016 / Accepted: 06.06.2016 / Published on line: 12.07.2016
}

\section{ABSTRACT}

The In situ Combustion Process (ISC) consists of a partial combustion of in situ oil, and its goal is to generate a combustion front able to make the oil flow. This combustion front will heat the oil's surrounding areas, achieving a reduction in oil viscosity and allowing its displacement into the production well. The aim of this investigation is to analyze and determine the parameters that influence the combustion process, highlighting the kinetics (activation energy, Arrhenius coefficient, and percentage of cracking for the production of coke) of three different models of chemical reactions and the air injection rate.

\section{KEYWORDS}

Enhanced Oil Recovery; thermal method, in situ combustion, simulation, kinetics combustion

\footnotetext{
${ }^{1}$ To whom all correspondence should be addressed.

Address: Laboratório de Estudos Avançados de Petróleo - LEAP, Universidade Federal do Rio Grande do Norte - UFRN, Campus Universitário Lagoa Nova, Natal/RN/Brasil.

ZIP Code: 59078-900 | Telephone: +55 84 99158-3382 |e-mail: jhonmt@ufrnet.br

doi:10.5419/bjpg2016-0008
} 


\section{INTRODUCTION}

Oil remains the main source of energy in the planet. However, the fast reduction of conventional oil reserves raises the interest in exploring heavy and extra heavy oil reservoirs. With this goal, researchers have developed different enhanced oil recovery techniques, one of them being the In Situ Combustion Process (ISC).

In Situ Combustion is the oldest thermal method of oil recovery (Burger \& Sahuquet, 1972; Chicuta \& Trevisan, 2009; Sarathi, 1999). This method consists on burning a portion of the oil in place to generate a combustion front capable of heating the surrounding areas, achieving a reduction in oil viscosity and allowing it to move towards the producer wells.

During ISC, ignition is maintained by continuous injection of air into the reservoir by the injection well. The common products generated after combustion are water and carbon dioxide. However, these products depend on the type of chemical reaction that generated them. The ignition of the oil in the reservoir may be spontaneous. If it is not spontaneous, the use of downhole heaters may be required (Adegbesan, 1982; Crookston et al.,1979; Fassihi et al., 1984; Sarathi, 1999).

Although it seems an easy process, ISC involves a series of complex mechanisms that difficult their representation through analytical and physical models and numerical simulation. It is classified as a high-risk process due to numerous problems in field application. The key causes of process failures are the incompatibility between the method and the reservoir characteristics, the poor quality of the preliminary study, or the complexity of representing, through numerical simulations, the different reactions and phenomena that occur during the process (Tarifa, 2014). However, when applied within the appropriate conditions, the in situ combustion has a high technical and economic potential (Lin et al. 1984; Mamora, 1993; Prats, 1982).

According to Mothé and Silva Jr. (2008), at the Northeastern region of Brazil there are on-shore heavy oil reservoirs located in the states of Rio Grande do Norte, Ceará, Sergipe, and Alagoas. To recover the oil, industry has several special recovery methods, and among the most used ones is the steam injection (Araujo, 2012).

The oil fields are considered mature between 15 and 35 years of production and some of them produce by steam, gas, and water injection. These types of fields may be good candidates for the implementation of the ISC (Ruiz, 2012; Schiozer, 2002).

The objective of this work is to study the implementation of the ISC in heavy oil reservoirs. For this, a semisynthetic reservoir with Northeastern Brazil features was used. The study aims to analyze and determine the parameters that may influence the process, highlighting the kinetics (activation energy, Arrhenius coefficient, and percentage of cracking for the production of coke during the process) behind three different models of chemical reactions (Tarifa, 2014).

\section{METHODOLOGY}

The present study analyzed a homogeneous reservoir model with characteristics from the Northeastern Brazil region. The reservoir characteristics are presented in Table 1. A finite aquifer was considered and a cap of gas was disregarded. The model represents a quarter five spot with a production well at one corner and other possible water injection well at the opposite corner.

The experiment used a multicomponent fluid system. The fluid model corresponded to an oil with similar properties to those found in some reservoirs from the Brazilian Potiguar basin. Its characteristics were as follows: $16.76{ }^{\circ} \mathrm{API}, \mathrm{RGO}$ of $6.09 \mathrm{~m}^{3} \mathrm{std} / \mathrm{m}^{3} \mathrm{std}$, and a thermal expansion coefficient of $6.8845 \times 10^{-4}{ }^{\circ} \mathrm{C}^{-1}$. According to the Brazilian National Agency of Petroleum, Natural Gas and Biofuels (ANP) classification, the oil used is considered a heavy oil $\left(10 \leq{ }^{\circ} \mathrm{API}<22\right)$.

Table 2 shows the information of the fluid present in the selected reservoir.

These components were grouped into seven (7) pseudo-components and two (2) components, as follows: heavy oil $\left(\mathrm{C}_{21-40+}\right)$, medium oil $\left(\mathrm{C}_{11-20}\right)$, light oil $\left(C_{6-10}\right)$, volatile oil $\left(C_{4-5}\right)$, gas $\left(C_{1-3}\right)$, inert gas $\left(\mathrm{CO}_{2}\right.$ and $\left.\mathrm{N}_{2}\right)$, coke $(\mathrm{C})$, and oxygen $\left(\mathrm{O}_{2}\right)$. 
Table 1. Reservoir properties.

\begin{tabular}{lc}
\hline Total Grid & $200 \mathrm{~m} \times 200 \mathrm{~m} \times 26 \mathrm{~m}$ \\
Dimensions of the reservoir $-(\mathrm{m})$ & $100 \times 100 \times 26$ \\
Block Numbers - i x j x k (m) & $15 \times 15 \times 12$ \\
Block Dimensions - i x j x k (m) & $6.667 \times 6.667 \times$ Variable \\
Initial Temperature of (oC) & $100.4(38)$ \\
Horizontal Permeability (mD) & 1000 \\
Vertical Permeability (mD) & 100 \\
Porosity (\%) & 23.0 \\
Connate Water Saturation - Swc (\%) & 35.0 \\
Deep of the Reservoir (m) & 200.0 \\
Reservoir HEIGHT (m) & 26 \\
Oil zone HEIGHT (m) & 20 \\
Initial Pressure of the Reservoir (kPa) & $1.993 \times 103$ \\
Rock compressibility (1/kPa) & $4.351 \times 10-4$ \\
Thermal Conductivity of the Rock J/(m*day*C) & 149535 \\
Thermal Conductivity of the Oil J/(m*day*C) & 11223.7 \\
Thermal Conductivity of the Gas J/(m*day*C) & 3741.23 \\
Thermal Conductivity of the Water J/(m*day*C) & 54200.3 \\
\hline
\end{tabular}

Table 2. Molar Fraction of fluid model components.

\begin{tabular}{cccc}
\hline Component & Molar Fraction & Component & Molar Fraction \\
\hline $\mathrm{CO}_{2}$ & 0 & $\mathrm{C}_{6}-\mathrm{C}_{12}$ & 0.10 \\
$\mathrm{~N}_{2}$ & 0 & $\mathrm{C}_{13}-\mathrm{C}_{20}$ & 0.2 \\
$\mathrm{C}_{1}-\mathrm{C}_{3}$ & 0 & $\mathrm{C}_{21}-\mathrm{C}_{40+}$ & 0.7 \\
$\mathrm{C}_{4}-\mathrm{C}_{5}$ & 0 & Coke & 0 \\
\hline
\end{tabular}

The application of the ISC caused some effects, such as an increase in reservoir temperature, which led to viscosity reduction, oil thermal expansion, distillation of the lighter components from the oil phase to the gas phase, and thermal cracking of higher molecular weight components into lighter components (Adegbesan, 1982; Coats, 1980; Crookston et al., 1979; Dabbous \& Fulton, 1974; Fassihi et al. 1984; Green \& Wilhite, 1998).

This study used three different models of chemical reactions. The objective was to observe their influence on the results obtained.

The first model applied (Model 1 ) was the one proposed by Coats (1980). This model is based on Crookston model (1979). Table 3 shows the oxidation reactions ( $R 1, R 2, R 3$, and $R 4)$, which occur with the three pseudo-components of oil (heavy, medium, and light) and coke (C). The products of those reactions are carbon dioxide
$\left(\mathrm{CO}_{2}\right)$, nitrogen $\left(\mathrm{N}_{2}\right)$, and water $\left(\mathrm{H}_{2} \mathrm{O}\right)$. The model also shows cracking reactions ( $\mathrm{R} 5$ and $\mathrm{R} 6$ ) of heavy and medium oils.

The second model (Model 2) was the one proposed by Belgrave et al. (1993). Table 3 shows one oxidation reaction (R4) with the coke (C). The products of this reaction were carbon dioxide $\left(\mathrm{CO}_{2}\right)$, nitrogen $\left(\mathrm{N}_{2}\right)$, and water $\left(\mathrm{H}_{2} \mathrm{O}\right)$. The model also shows cracking reactions of heavy and medium oils ( $R 5$ and R6), and presents low temperature reactions ( $R 7, R 8$, and $R 9$ ). The cracking reactions and the low temperature reactions supply the fuel to the oxidation reaction.

Finally, the third model used (Model 3) was a modification of the first two models presented above (Coats, 1980; Belgrave et al., 1993). Table 3 shows the oxidation reactions ( $R 1, R 2, R 3$, and R4), which occur with the three pseudo-components oil (heavy, medium, and light) and coke (C), having as 
Table 3. Chemical reactions of Model 1, Model 2, and Model 3.

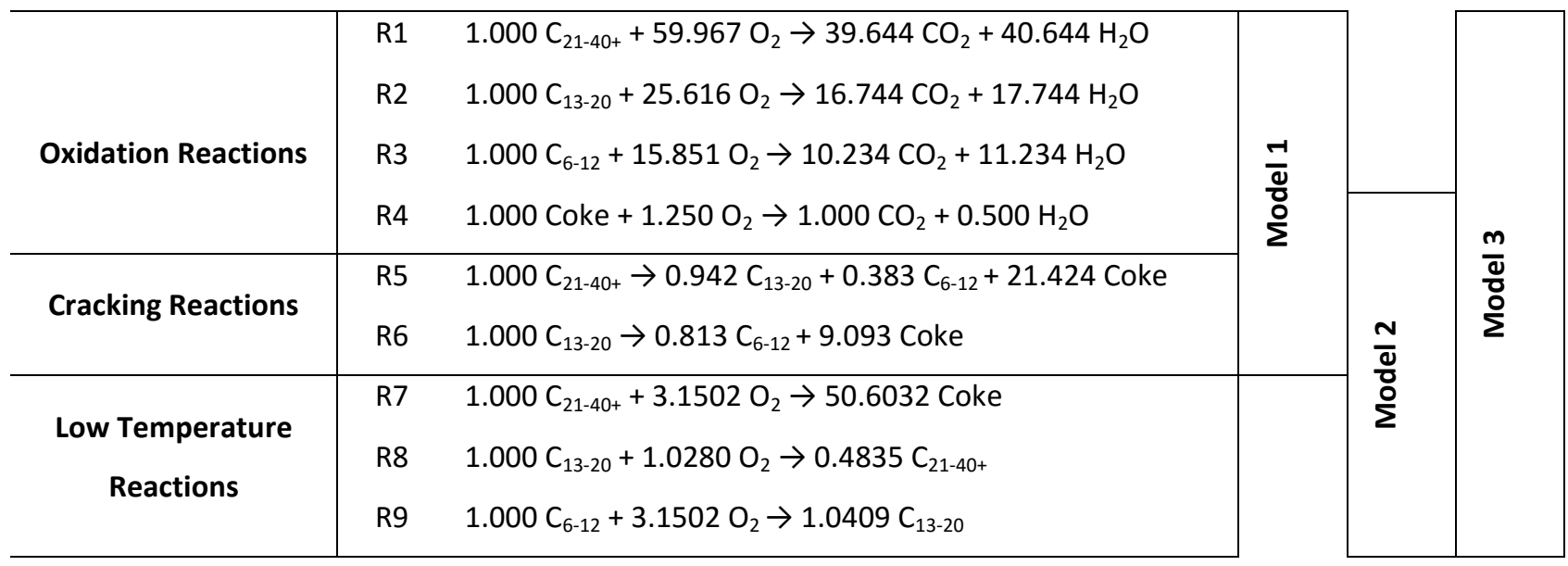

Table 4. Kinetic values for Models 1, 2, and 3 (Coats, 1980; Belgrave et al., 1993; Dabbous \& Fulton, 1974).

\begin{tabular}{lcccccc} 
& \multicolumn{3}{c}{ Model 1 } & \multicolumn{3}{c}{ Model 2 - Model 3 } \\
\hline & Arrhenius* & $\begin{array}{c}\text { Ea } \\
\text { (BTU/lb-mol) }\end{array}$ & $\begin{array}{c}\Delta \mathbf{H} \\
\text { (BTU/lb-mol) }\end{array}$ & Arrhenius* & $\begin{array}{c}\text { Ea } \\
\text { (BTU/lb-mol) }\end{array}$ & $\begin{array}{c}\Delta \mathbf{H} \\
\text { (BTU/lb-mol) }\end{array}$ \\
\hline R1 & $3.02 \times 10^{10}$ & 32785 & $8.14 \times 10^{5}$ & $7.25 \times 10^{11}$ & 59330 & $1.28 \times 10^{7}$ \\
R2 & $3.02 \times 10^{10}$ & 32785 & $4.52 \times 10^{6}$ & $7.25 \times 10^{11}$ & 59330 & $2.92 \times 10^{6}$ \\
R3 & $3.02 \times 10^{10}$ & 32785 & $2.10 \times 10^{6}$ & $7.25 \times 10^{11}$ & 59330 & $2.92 \times 10^{6}$ \\
R4 & 416.7 & 28800 & $2.3 \times 10^{5}$ & $9.98 \times 10^{5}$ & 25200 & $2.25 \times 10^{5}$ \\
R5 & $4.17 \times 10^{5}$ & 28800 & $2.00 \times 10^{4}$ & $1.00 \times 10^{7}$ & 27000 & $4.00 \times 10^{4}$ \\
R6 & $4.17 \times 10^{5}$ & 28800 & $2.00 \times 10^{4}$ & $1.00 \times 10^{7}$ & 27000 & $4.00 \times 10^{4}$ \\
R7 & - & - & - & $4.71 \times 10^{10}$ & 31600 & $1.85 \times 10^{5}$ \\
R8 & - & - & - & $4.71 \times 10^{10}$ & 31600 & $1.86 \times 10^{5}$ \\
R9 & - & - & - & $4.71 \times 10^{10}$ & 31600 & $1.87 \times 10^{5}$ \\
\hline
\end{tabular}

* The pre-exponential factor units depend on the type of chemical reaction.

products carbon dioxide $\left(\mathrm{CO}_{2}\right)$, nitrogen $\left(\mathrm{N}_{2}\right)$, and water $\left(\mathrm{H}_{2} \mathrm{O}\right)$. The model shows cracking reactions (R5 and R6) of heavy and middle oils and presents low temperature reactions ( $R 7, \mathrm{R} 8$, and R9). As mentioned, cracking and low temperature reactions are responsible for providing the fuel for oxidation reactions.

The chemical reactions of Model 1, Model 2, and Model 3 were adjusted to suit the characteristics of the fluid from the Northeastern Brazil region.

The activation energy (Ea) is the energy required for the reaction to start and the enthalpy of the reaction $(\Delta H)$ is the energy released from each mole that reacted during the process. The pre-exponential factor (Ar) is the Arrhenius constant (Dabbous \& Fulton, 1974; Fassihi et al.,
1984; Mamora, 1993; Moore et al., 1999). Table 4 presents the data used for each chemical reaction model studied.

The aim of this investigation is to analyze and determine the parameters that influence the process of the combustion, highlighting the kinetics of the process (activation energy, Arrhenius coefficient, and percentage of cracking for the production of coke).

Initial simulations determined the most relevant parameters of the ISC and, then, the sensitivity analysis of some parameters on the kinetics of the reactions and the oil flow in the oil recovery at different times. A full factorial design was used ( 3 factors at 3 levels), totaling 27 simulations for the models in question. 
Table 5. Parameters of the sensitivity analysis.

\begin{tabular}{|c|c|c|c|}
\hline \multirow[b]{2}{*}{ Parameters } & \multicolumn{3}{|c|}{ Level } \\
\hline & -1 & 0 & +1 \\
\hline Ea-Ar (Multiplier \%) & 25 & 100 & 175 \\
\hline Craq (\%) & 25 & 50 & 75 \\
\hline $\operatorname{Qinj}\left(m^{3} /\right.$ day) & 7500 & 15000 & 22500 \\
\hline
\end{tabular}

The minimum levels are represented as (-1), intermediate as (0), and maximum as $(+1)$. The intervals selected for analysis of the parameters are shown in Table 5. Ea-Ar is the activation energy pre-exponential factor in percentage, the Craq in percentage is the amount of coke that forms during cracking reactions, and Qinj is the air injection rate.

Table 5 shows that Craq (\%) refers to the amount of a given compound (long molecular chain) that divides into other components of lower molecular weight due to the increase in pressure, temperature, or due to both.

$$
\begin{aligned}
& \mathrm{a} \mathrm{HO} \rightarrow \mathrm{b} \mathrm{MO}+\mathrm{c} \mathrm{LO}+\mathrm{d} \text { Coke } \\
& u^{L} \underbrace{L} \\
& 75 \% \quad 25 \%
\end{aligned}
$$

The example shown above represents a $25 \%$ cracking, where the heavier compound $(\mathrm{HO})$ was divided into other components of shorter molecular chains (MO, LO, and coke); where a, b, c, and $\mathrm{e}$ are the corresponding stoichiometric coefficients. The reactions six and seven (R6, R7) were obtained using this concept.

Various simulations aimed at evaluating the effect of each parameter separately, that is, Ea-Ar, Craq, and Qinj. Thus, it becomes possible to obtain a good understanding of the productivity gain in the method.

The commercial software used were from Computer Modelling Group (CMG) and the modules employed to perform this work were: Winprop (to model the fluids), Builder (to create the reservoir model), and Stars (to run all study cases) - version 2014.10.

\section{RESULTS AND DISCUSSIONS}

At first, the oil recovery was compared with the ISC (base model) versus primary production, as shown in Figure 1 . One can observe that the production is similar for both models up until the seventh year of production, which shows an oil recuperation of approximately $10 \%$. However, after this point, the oil bank obtained with the ISC reaches the producer well allowing an increase of oil recovery, achieving $53.2 \%$ at 20 years of production, while primary recovery factor is of about $16.6 \%$. The difference between the two curves is approximately 36 percentage points and shows that the ISC improved the results if compared to the primary recovery. The simulated time was 20 years.

Model 1 was analyzed, using three cases representing the highest, intermediate, and lowest values of the activation energy pre-exponential factor, as shown in Figure 2. Those cases were "Case 5," "Case 14," and "Case 23," respectively. To choose these cases, the cracking percentage and air injection rate were set as constants, to make it easier to observe the influence of the activation energy pre-exponential factor on its own, within the combustion process.

In Figure 2, one can observe the behavior of the $\mathrm{RF}$ as a function of time. The cracking percentage was maintained constant at $50 \%$ and the air injection rate at $15000 \mathrm{~m}^{3} / \mathrm{d}$. The Ea- Ar values used for the analysis were $25 \%, 100 \%$, and $175 \%$.

The expected behavior was that the higher the value of the activation energy was, the lower the RF obtained would be, and so it was observed. "Case 23" had the highest activation energy value and the lowest RF. Since the values of Ea-Ar were 


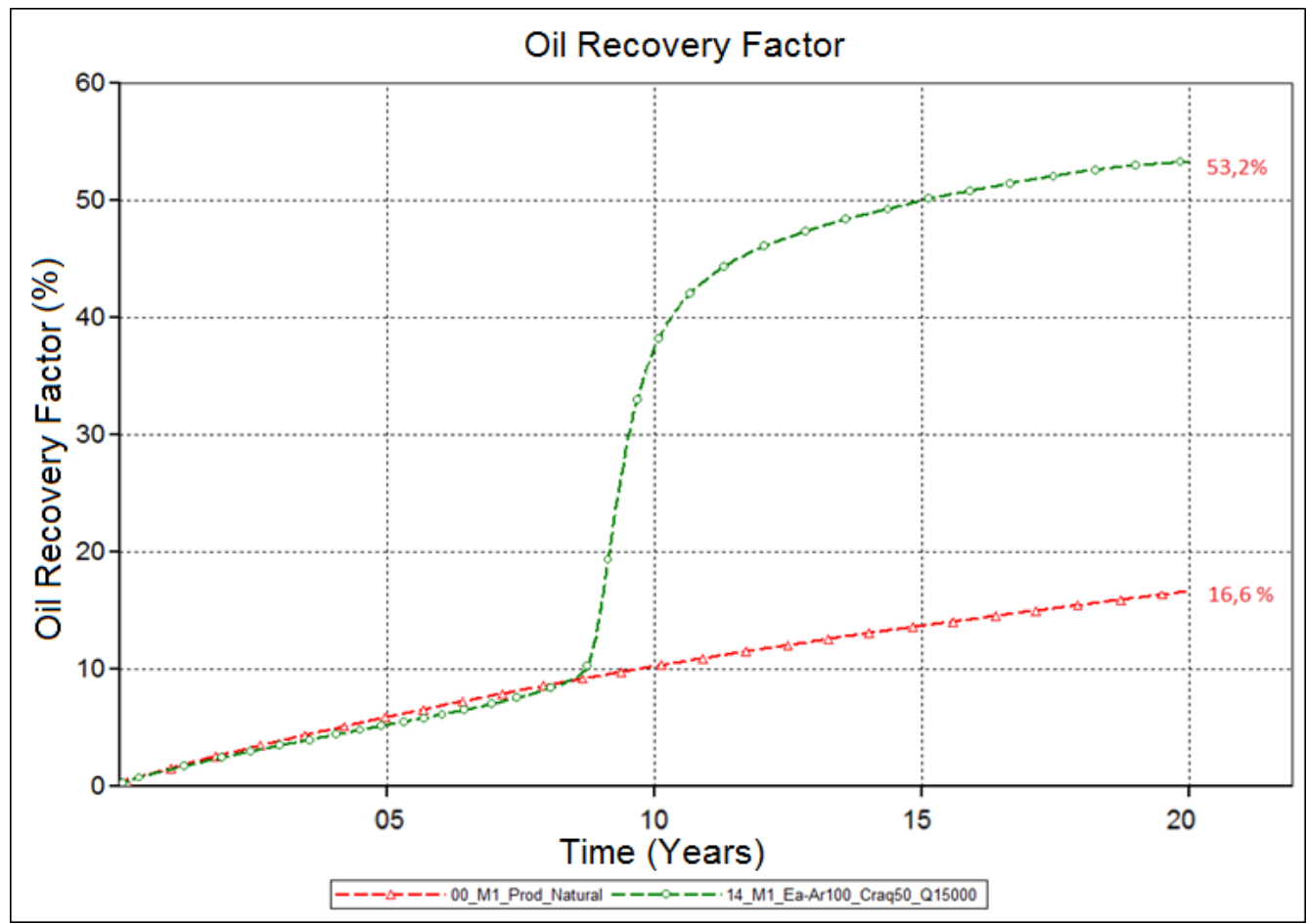

Figure 1. Oil recovery factor of base model vs. primary production.

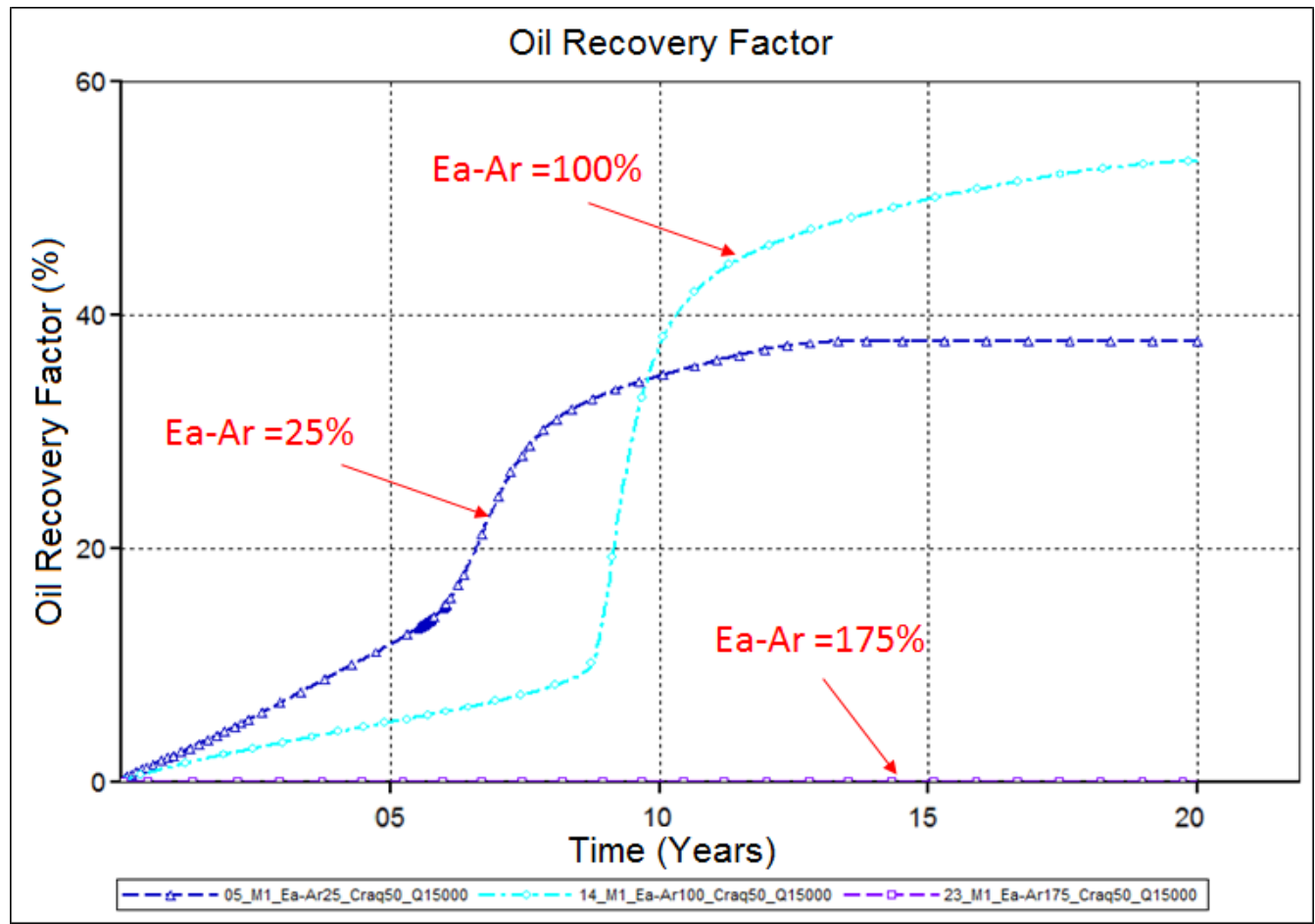

Figure 2. Oil Recovery Factor in function of Ea-Ar.

very high, the corresponding chemical reactions did not occur, leading to a poor oil recovery factor (Dabbous \& Fulton, 1974; Fassihi et al. 1984; Lin et al., 1984).
Continuing with the analysis of the results as a function of Ea-Ar, there was a comparison between "Case 5" and "Case 14." Between the two, "Case 5" had lower activation energy. One could observe that during the first almost 9 years its RF was 


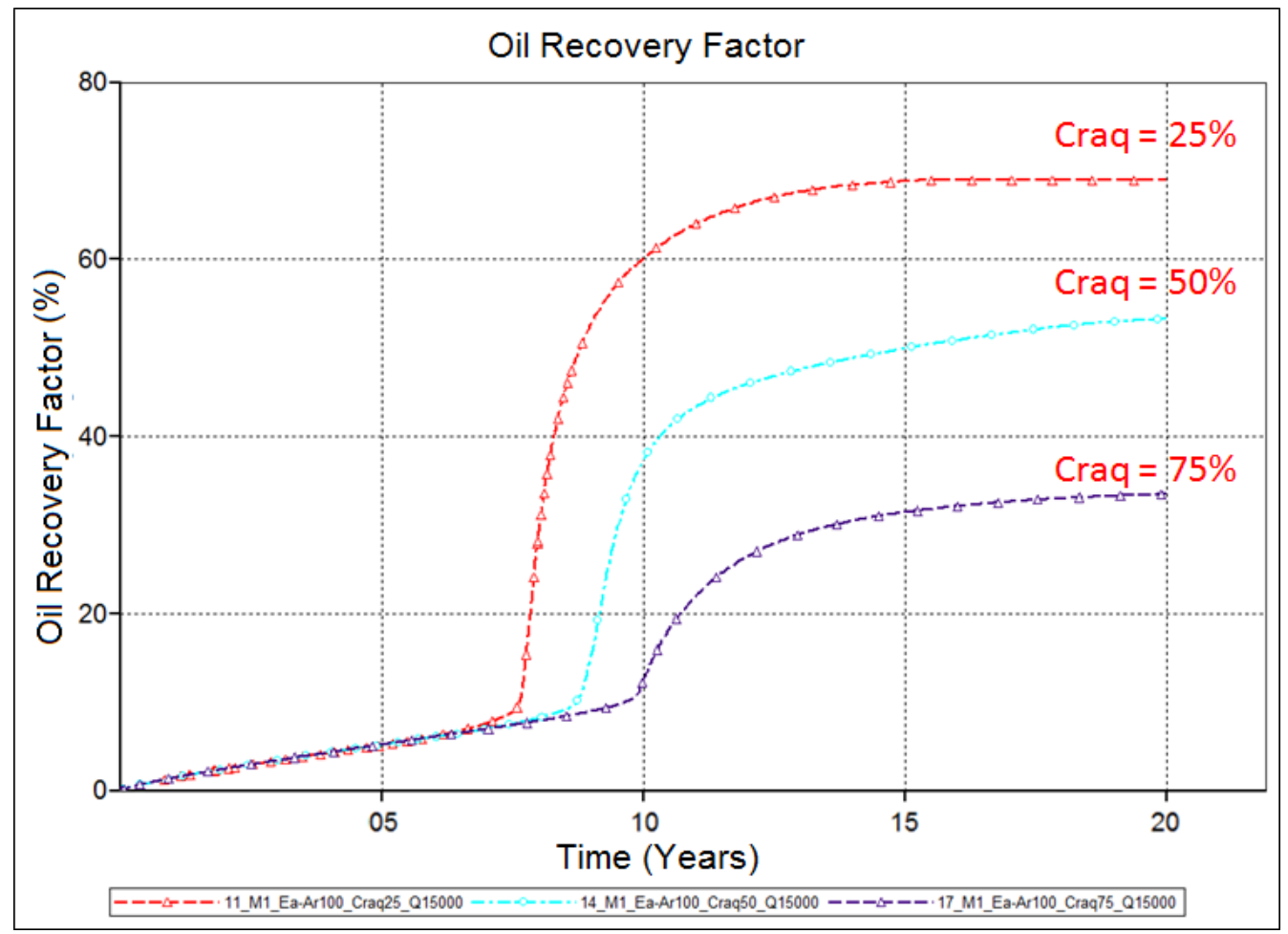

Figure 3. Oil Recovery Factor in function of Craq.

higher, but after that time "Case 14" started to show a better RF, going against expectations. However, that behavior can be explained as a function of the large amount of coke that was formed inside the reservoir for "Case 5," which might have prevented the oil from flowing easily to the producing wells. This issue is mentioned later in this paper.

As for the Ea-Ar, another analysis of Model 1, based on the percentage of cracking, was made also choosing three cases representing the highest, intermediate, and lowest values of this parameter, as shown in Figure 3. The Ea-Ar and Qinj values were set constant, so it was possible to observe the influence of the cracking percentage in the combustion process.

Figure 3 shows the behavior of RF as a function of time, while the Ea-Ar values remained constant at $100 \%$, and the Qinj of air at $15000 \mathrm{~m}^{3} /$ day. The values of Craq used for the analysis were $25 \%, 50 \%$, and $75 \%$.

It was observed that the lower the cracking percentage (Craq), the higher was the RF. The Craq variable determines the amount of oil that will convert into coke inside the reservoir. The more coke is formed, the less oil available to be produced.

It is important to say that the amount of coke that is formed along the ISC, depends on the different reactions and defines the quantity of fuel used in the process. The success of ISC depends on the quantity of fuel formed through cracking reactions (R5, R6) (Crookston et al., 1979; Dabbous \& Fulton, 1974; Rodriguez, 2004).

Right after, an analysis was performed for three cases based on the air injection rate, as shown in Figure 4. Once again, the cases represented the highest, intermediate, and lowest values of the parameter studied. The values of Ea-Ar and Craq were kept constant at $100 \%$ and $50 \%$, respectively, in order to observe the influence of the air injection rate in the combustion process.

Figure 4 shows the RF as a function of time. The Qinj values used for the analysis were $7500 \mathrm{~m}^{3} / \mathrm{d}$, $15000 \mathrm{~m}^{3} / \mathrm{d}$, and $22500 \mathrm{~m}^{3} /$ day. When value of Qinj increased, the arrival of the bank of oil was anticipated to the production well. Furthermore, the results showed that the Qinj influenced the amount of oil recovered. 


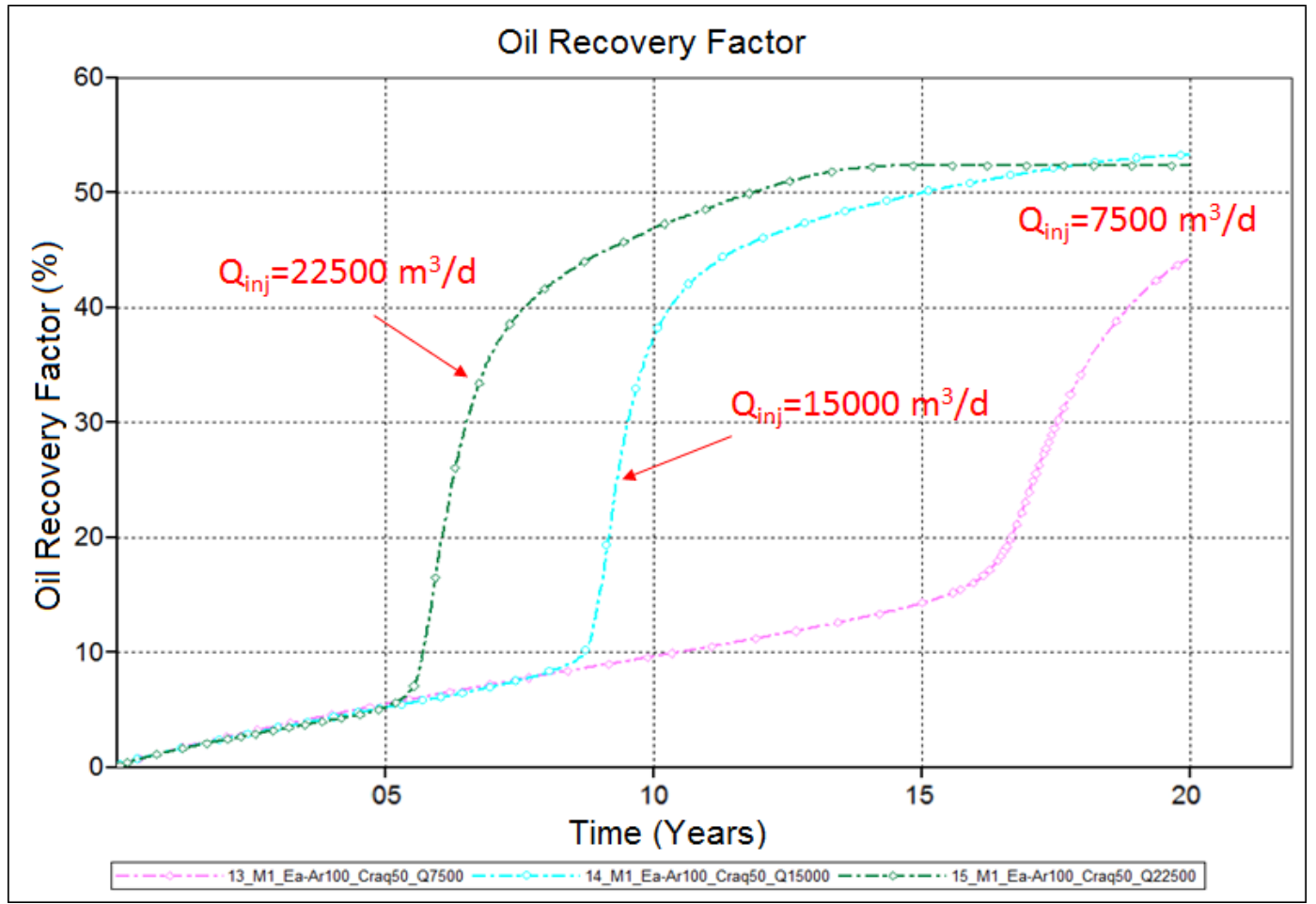

Figure 4. Oil Recovery Factor in function of Qinj.

As observed in Figure 4, the production of oil for every case presents a significant increment, known as the arrival of the bank of oil to the production well, which is due to the advance of the combustion front. This increase occurs at different times, depending on the different values of Qinj for each case studied.

In "Case 15," Qinj $22500 \mathrm{~m}^{3} /$ day, its curve showed that the production of the bank of oil happened after 5 years, while in "Case 14" the production of the bank of oil happened after 7 years, and, finally, in the "Case 13" it happened after 15 years.

The analysis of Qinj generally aims at conducting an economic study of a project, since the injection of air could slow or stop after the production of the bank of oil (Green \& Wilhite, 1998; Prats, 1982; Rojas et al., 2010).

\subsection{Comparison between the proposed models}

The different models (Model 1, Model 2, and Model 3) of chemical reactions had a similar behavior in the modeling of the combustion front displacement in the reservoir, but this behavior was due to the different values of kinetic reactions.
It is known that each model has different reactions, which are responsible for the combustion behavior in the reservoir. It is also important to recognize the complexity of numerical modeling of the combustion process through chemical reactions proposed by different models.

Table 6 presents a summary of the cases analyzed. Cases "05, 14, and 23" were used for the analysis of Ea-Ar; cases "11, 14, and 17" were used for analysis of Craq; and cases "13, 14, and 15" were used to analyze the Qinj, representing the highest, intermediate, and the lowest values of every parameter, respectively. The results obtained are a function of the RF.

Table 6 shows the RF of each model of reactions proposed. There is a variation in the values of the oil recovery in each of the cases examined for a period of 20 years.

The Figure 5 shows the RF of the base case "14" of each of the three models of chemical reactions. This figure shows that the base case of Model 1 had a higher RF if compared to Models 2 and 3, and those models had a similar RF between them. The behavior is due to Model 1 not having LTO reactions. Models 2 and 3, do have LTO reactions, one of these chemical reactions is responsible for 
Table 6. Recovery Factor of the models.

\begin{tabular}{l|cccc}
\cline { 2 - 5 } & Case & Model 1 & Model 2 & Model 3 \\
\hline & 05 & 37.85 & 39.14 & 38.93 \\
& 11 & 68.91 & 77.91 & 78.04 \\
& 13 & 44.31 & 48.19 & 48.30 \\
& 14 & 53.26 & 46.98 & 46.99 \\
& 15 & 52.33 & 45.08 & 45.07 \\
& 17 & 33.49 & 27.51 & 27.47 \\
& 23 & 0.07 & 0.07 & 0.07 \\
\hline
\end{tabular}

transforming a given amount of oil into coke, resulting in a decrease of the amount of oil that is produced when compared to Model 1 . It is important to say that the different reactions are responsible for the fluid change inside the reservoir (Adegbesan, 1982; Mamora, 1993).

To notice the differences between the three proposed models, a comparison of the base case models was performed. The parameter chosen to make the comparison was the temperature. Since Models 2 and 3 have low-temperature reactions, these reactions influence the final temperature of the process. Figure 6 shows the temperature maps for the base case "14" of each proposed model in 4 different dates ( 6 months, 5, 10, and 20 years) specified at the top of each map.

Figure 6 is divided into three columns and four rows. Each column represents the base case of each model, while each row represents a different time. The images have descriptive details for a better understanding.

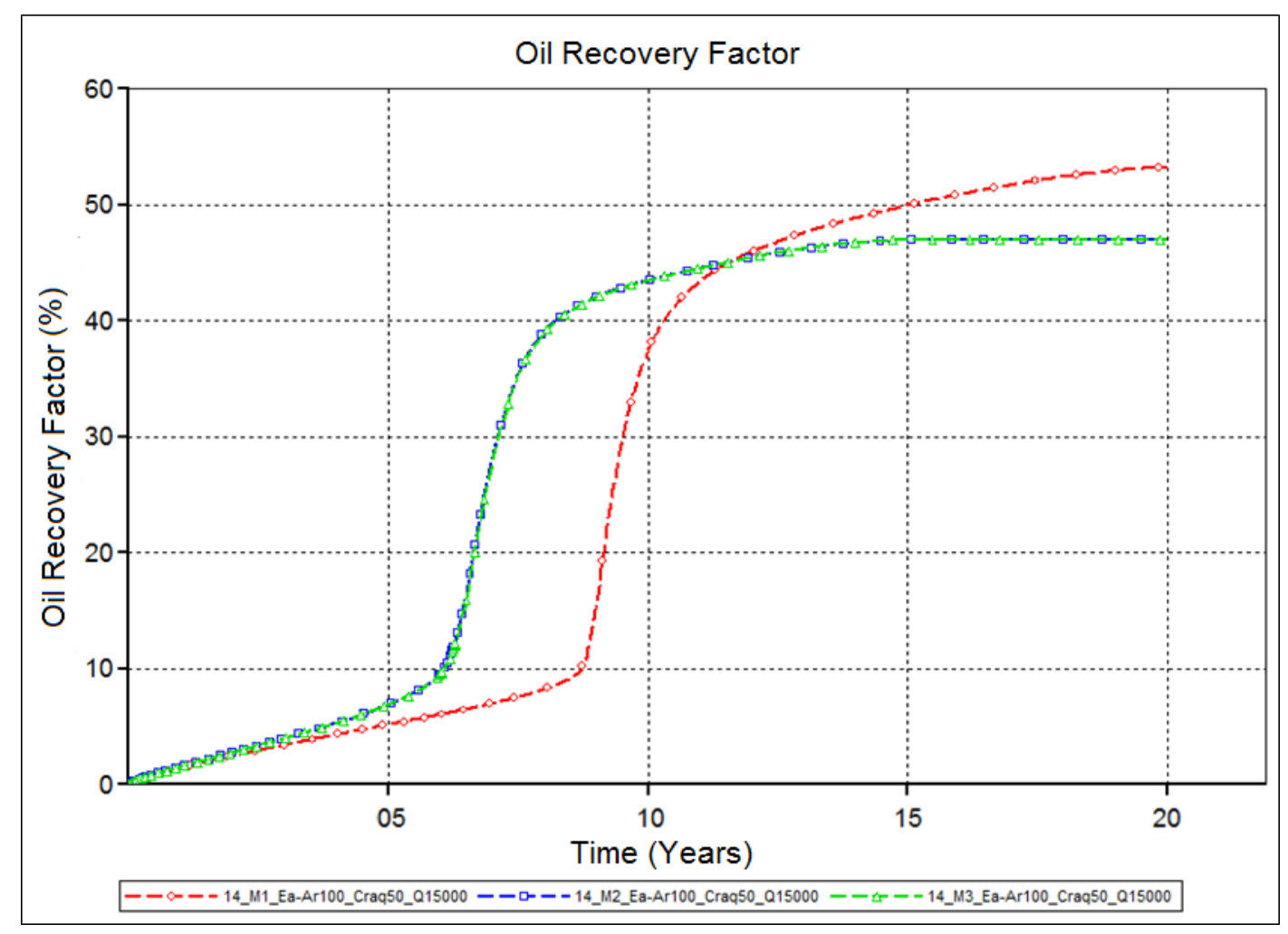

Figure 5. Oil Recovery Factor of base case for Models 1, 2, and 3. 


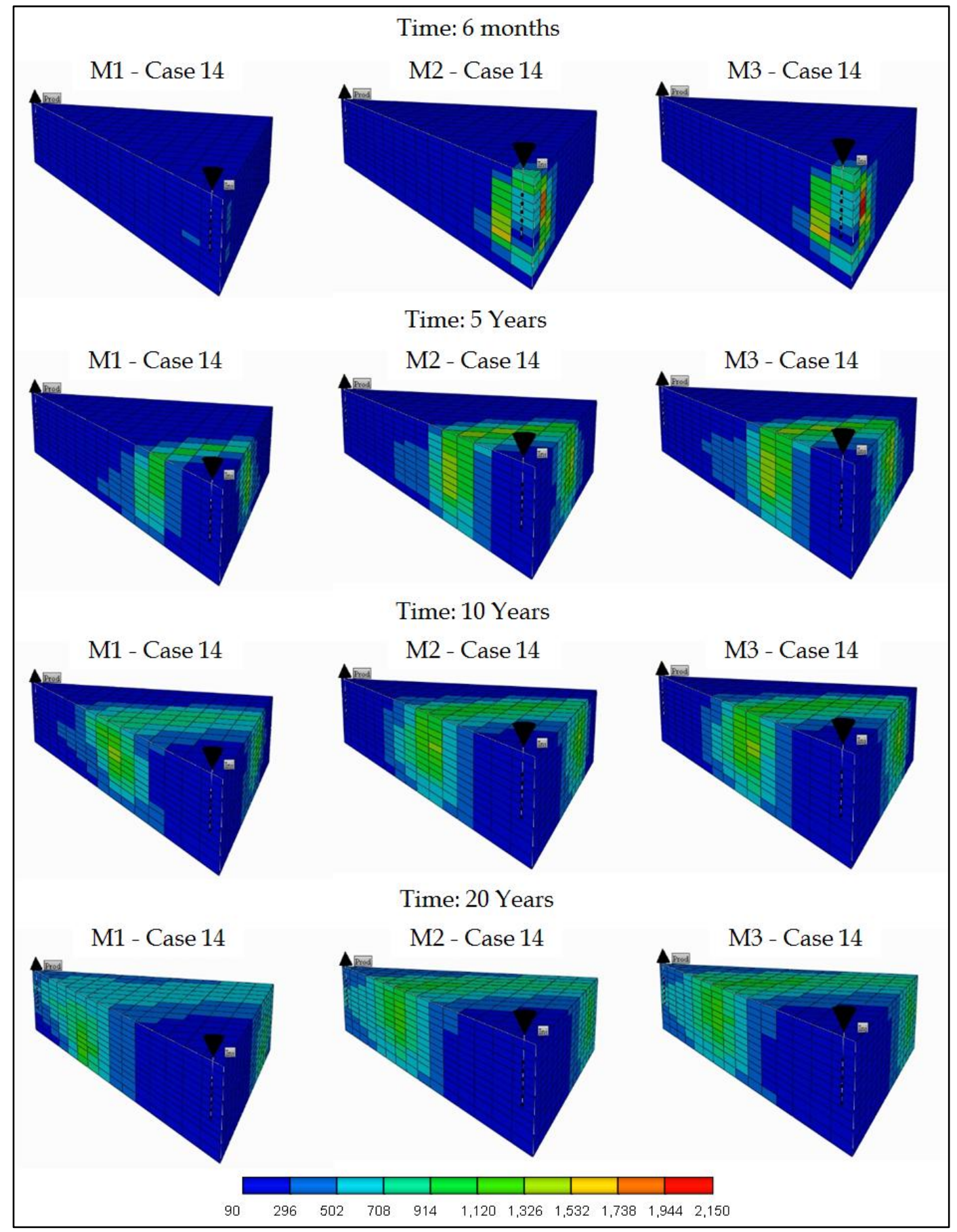

Figure 6. Temperature maps for Models 1, 2, and 3 base cases.

Figure 6 shows an increase of temperature in the sixth month injections for Models 2 and 3 . In both cases, the low temperature reactions allowed the combustion process to start earlier if compared with Model 1. The maximum temperature achieved by "Case 14" from Model $11600^{\circ} \mathrm{F}\left(870^{\circ} \mathrm{C}\right)$ approximately. The "case 14" for Models 2 and 3 reached a temperature of nearly $2100^{\circ} \mathrm{F}\left(1150^{\circ} \mathrm{C}\right)$.
The temperatures of Models 2 and 3 are similar due to the presence of low temperature reactions. These reactions provide the energy required for the combustion process to be started faster than in the Model 1. This behavior is consistent according to the literature consulted (Adegbesan, 1982; Belgrave et al., 1993). 


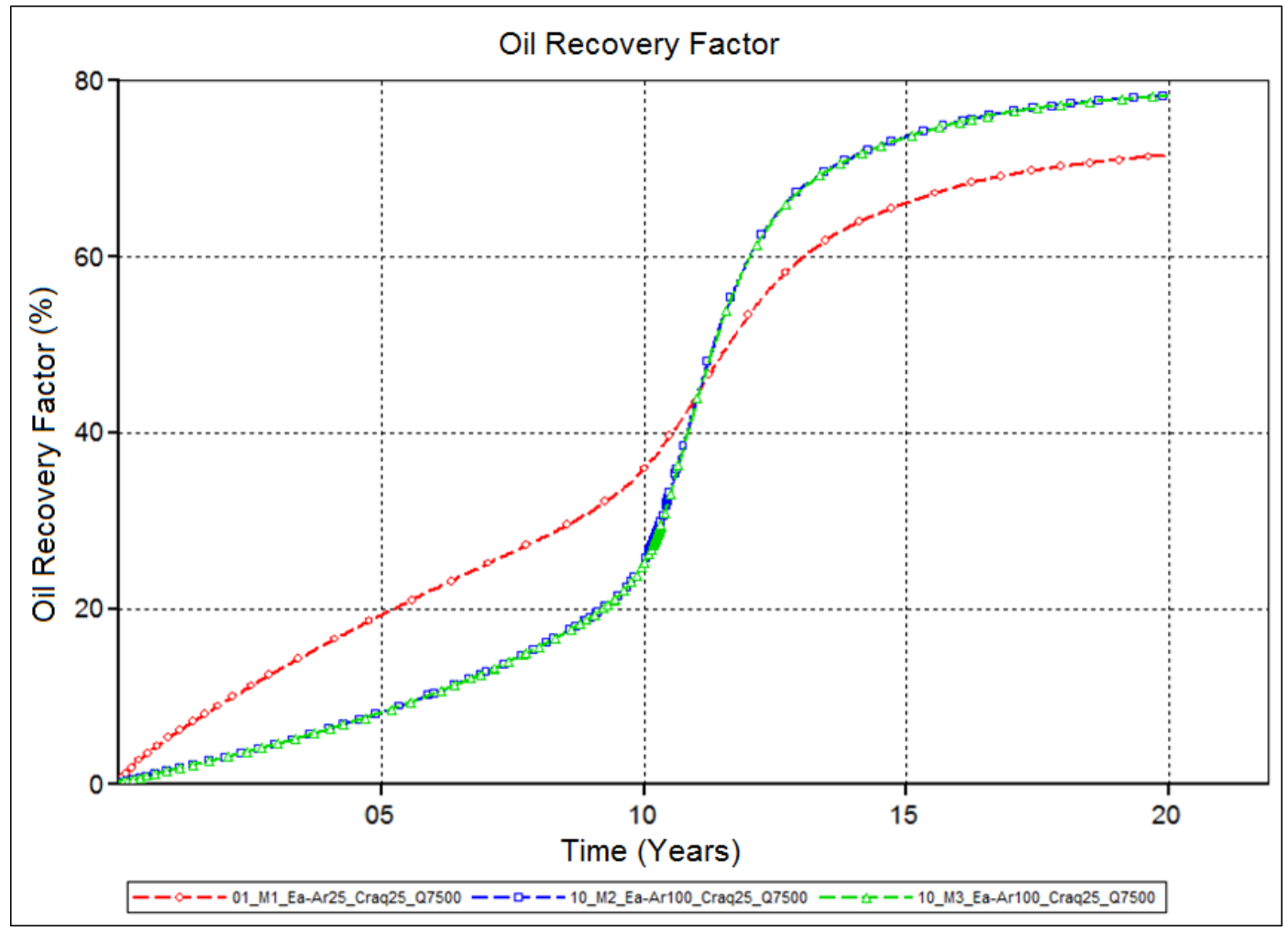

Figure 7. Oil Recovery Factor with the best results from Models 1, 2, and 3.

After analyzing the various parameters, a comparison between the cases that showed the highest results in terms of recovery factor between all three models was performed, regardless of being or not the base case of each model. The cases that showed the highest RF were "Case 1" from Model 1, "Case 10" from Model 2, and "Case 10" from Model 3, as shown in Figure 7.

Figure 7 shows that "Case 1" (Model 1) has a higher RF in the first 10 years of the project, after that time the production decreases when compared to "Case 10" of Models 2 and 3, which show a higher RF. This behavior is due to the values of Ea-Ar of the chemical reactions of each Model. The value of Ea-Ar for "Case 1" of Model 1 was $25 \%$, which means that a larger amount of coke was formed ahead the bank of oil, making it difficult to displace the remaining fluent oil to the production well.

Continuing with the comparison of the cases with the best results of each model, Figure 8 shows the temperature maps for "Case 1" of Model 1 , "Case 10" of Models 2 and 3. These temperatures were compared in four different times $(6$ months, 5,10 , and 20 years), specified at the top of each map.

Figure 8 shows an increase in temperature in the sixth month of injection for all models. In "Case 1" of Model 1, the increment of temperature was due to the low values of Ea-Ar that allowed the start of combustion, for "Case 10" of Models of 2 and 3 , the rise of temperature was due to the presence of the low temperature reactions, which caused a progressive increase in temperature. The maximum value of temperature that the models presented was at the beginning of the process. The "Case 1" of Model 1 reached a temperature of nearly $1450^{\circ} \mathrm{F}\left(787^{\circ} \mathrm{C}\right)$, the "Case $10^{\prime \prime}$ of Models 2 and 3 reached a temperature of approximately $1940^{\circ} \mathrm{F}\left(1060^{\circ} \mathrm{C}\right)$.

From the 15th year of the project on, there was a reduction of temperature in "Case 10" of Models 2 and 3, while in "Case 1" the temperature of the combustion front remained higher. This phenomenon was possible due to a combination of factors such as the air injection rate $\left(7500 \mathrm{~m}^{3} / \mathrm{d}\right)$ 


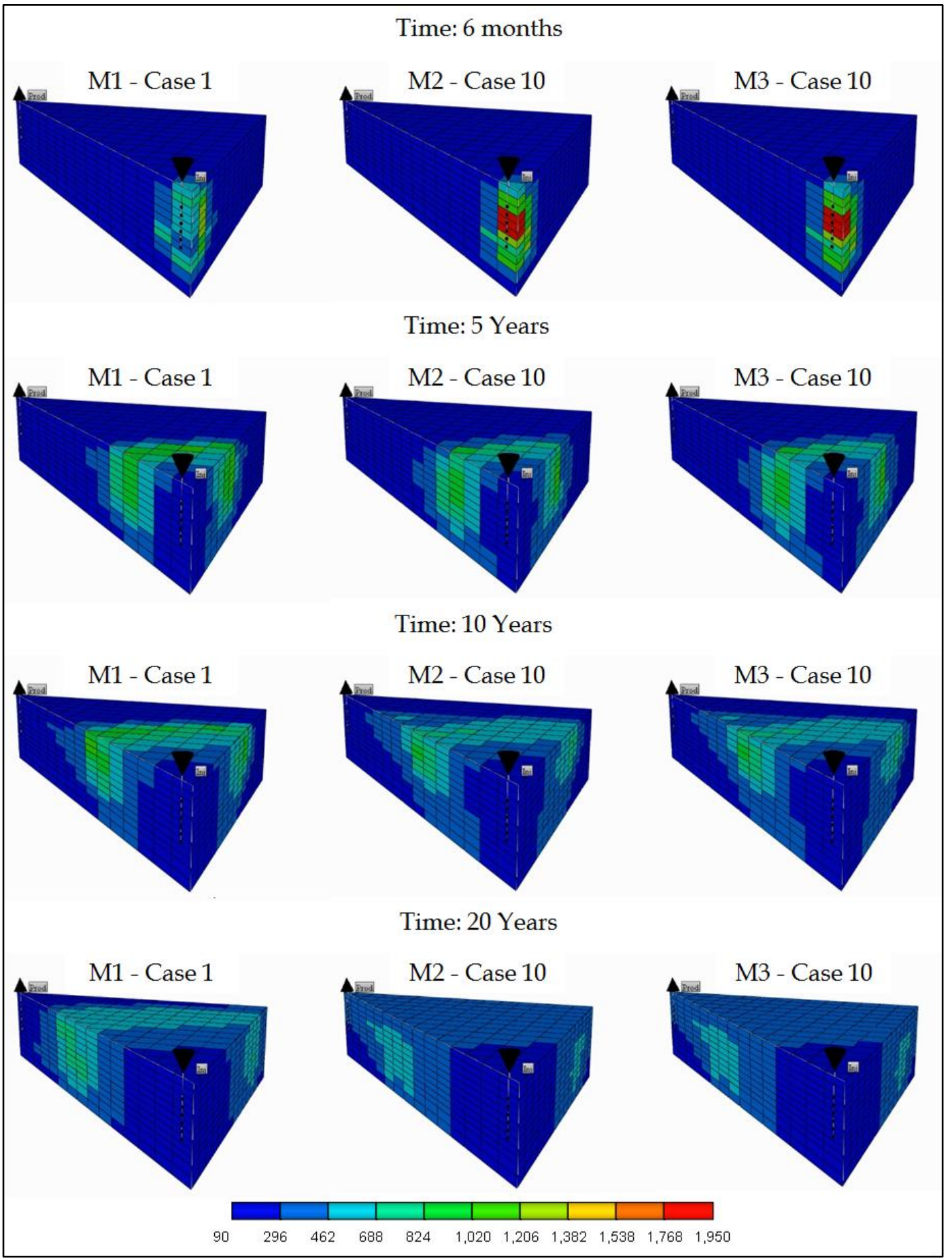

Figure 8. Temperature maps for "case 1" of Model 1 and "case 10" of Models 2 and 3.

and the cracking percentage of $25 \%$, but the main parameter was the absence of low temperature reactions. Since one of the functions of these LTO reactions is to form oxygenated compounds that will be transformed into heavier compounds, the cycle between the cracking and the formation of heavy compounds is continuous (Adegbesan, 1982; Belgrave et al., 1993).
Table 7 resumes the values of RF, volume of oxygen $\left(\mathrm{O}_{2}\right)$ that was injected, produced and consumed in the process for cases with a major RF and for the base cases related to the models.

It is observed in Table 7 that the percentage of $\mathrm{O}_{2}$ consumed for "Case 14" of Model 1 is approximately $95 \%$, the value of the $\mathrm{O}_{2}$ consumed for "Case 14" of Models 2 and 3, which was around 
Table 7. Values of the analyzed cases for the different Models.

\begin{tabular}{lcccccc} 
& \multicolumn{2}{c}{ Model 1 } & \multicolumn{2}{c}{ Model 2 } & \multicolumn{2}{c}{ Model 3 } \\
\cline { 2 - 7 } & Case 14 & Case 1 & Case 14 & Case 10 & Case 14 & Case 10 \\
\hline RF (\%) & 53.26 & 71.55 & 46.98 & 7832 & 46.99 & 78.30 \\
$\mathbf{O}_{\mathbf{2}}$ Injected $\left(\mathbf{m}^{\mathbf{3}}\right)$ & $2.30 \times 10^{7}$ & $1.15 \times 10^{7}$ & $2.30 \times 10^{7}$ & $1.15 \times 10^{7}$ & $2.30 \times 10^{7}$ & $1.15 \times 10^{7}$ \\
$\mathbf{O}_{\mathbf{2}}$ Produced $\left(\mathbf{m}^{\mathbf{3}}\right)$ & $1.13 \times 10^{6}$ & 0 & $7.32 \times 10^{5}$ & $1.40 \times 10^{5}$ & $7.31 \times 10^{5}$ & $1.39 \times 10^{5}$ \\
$\mathbf{O}_{\mathbf{2}}$ Consumed $\left(\mathbf{m}^{\mathbf{3}}\right)$ & $2.19 \times 10^{7}$ & $1.15 \times 10^{7}$ & $2.23 \times 10^{7}$ & $1.14 \times 10^{7}$ & $2.23 \times 10^{7}$ & $1.14 \times 10^{7}$ \\
$\mathbf{O}_{\mathbf{2}}$ Consumed (\%) & 95.09 & 100 & 96.82 & 98.78 & 96.82 & 98.79 \\
\hline
\end{tabular}

Table 8. Higher results between Models 1, 2, and 3.

\begin{tabular}{|c|c|c|c|c|c|c|c|}
\hline & & \multicolumn{2}{|c|}{ Model 1-Case 1} & \multicolumn{2}{|c|}{ Model 2-Case 10} & \multicolumn{2}{|c|}{ Model 3-Case 10} \\
\hline & & $\mathrm{m}^{3}$ & $\%$ & $\mathrm{~m}^{3}$ & $\%$ & $\mathrm{~m}^{3}$ & $\%$ \\
\hline & Volume of oil (VOIP) & 24933 & 100 & 24933 & 100 & 24933 & 100 \\
\hline & $\mathrm{Np}$ & 4807 & 19.28 & 2042 & 8.19 & 2042 & 8.19 \\
\hline \multirow[t]{3}{*}{5 years } & Vol. of oil Res. & 13911 & 55.79 & 20085 & 80.55 & 20085 & 80.55 \\
\hline & Oil consumed + Coke & 6213 & 24.92 & 2807 & 11.26 & 2804 & 11.25 \\
\hline & $N p$ & 8956 & 35.92 & 6295 & 25.25 & 6255 & 25.09 \\
\hline \multirow[t]{3}{*}{10 years } & Vol. of oil Res. & 9793 & 39.28 & 14577 & 58.47 & 14660 & 58.80 \\
\hline & Oil consumed + Coke & 6183 & 24.8 & 4059 & 16.28 & 4016 & 16.11 \\
\hline & $\mathrm{Np}$ & 16480 & 66.10 & 18353 & 73.61 & 18338 & 73.55 \\
\hline \multirow[t]{3}{*}{15 years } & Vol. of oil Res. & 1842 & 7.39 & 1571 & 6.30 & 1571 & 6.30 \\
\hline & Oil consumed + Coke & 6609 & 26.51 & 5009 & 20.09 & 5024 & 20.15 \\
\hline & $\mathrm{Np}$ & 17839 & 71.55 & 19527 & 78.32 & 19522 & 78.30 \\
\hline \multirow[t]{2}{*}{20 years } & Vol. of oil Res. & 269 & 1.08 & 311 & 1.25 & 311 & 1.25 \\
\hline & Oil consumed + Coke & 6824 & 27.37 & 5093 & 20.43 & 5098 & 20.45 \\
\hline
\end{tabular}

97\%. The values of Ea-Ar, Craq, and Qinj are equal for all 3 models. This behavior is consistent according to the literature reviewed (Adegbesan, 1982; Belgrave et al., 1993), since low temperature reactions require an amount of $\mathrm{O}_{2}$ to react, polymerize, and, then, form heavier compounds.

For "Case 1" of Model 1 it was observed that the $\mathrm{O}_{2}$ was consumed completely. This was due to the low value of Ea-Ar, which allowed that the combustion process could be maintained through the process. Another factor that helped the described phenomenon was the Qinj.

"Case 10" of Models 2 and 3 consumed about $98 \%$ of $\mathrm{O}_{2}$. For these cases, the value of the Ea-Ar was $100 \%$. The value reached at the end of the project to the combustion front couldn't be selfsustained so the temperature decreased. Figure 8 shows graphically what was explained above.
Table 8 shows the values of cumulative oil produced ( $\mathrm{Np}$ ), the volume of oil in the reservoir, the amount of fuel consumed by the combustion front, and the amount of coke remaining in the reservoir in $5,10,15$, and 20 years.

Table 8 shows that the amount of oil consumed and the coke formed for the "Case 10" of Models 2 and 3 increases progressively throughout the project. This behavior is expected considering that the Ea-Ar of Models 2 and 3 was $100 \%$, thus, due to the values of Ea-Ar the production of coke and the quantity of oil-coke that is consumed is progressive; it increases as the combustion front moves until the production well.

Also in Table 8 it is observed that for the "Case 1 " of Model 1, the amount of coke formed and the amount of oil-coke consumed during the first 5 years was greater than during 10 years. This 
behavior is due to the value of Ea-Ar being 25\%, which means that the initial amount of coke formed by cracking reactions was significant. After 10 years, one can observe a decrease in this amount due to the displacement of the combustion front. At 15 and 20 years of the project, one can see that the amount of coke formed and the amount of oil-coke consumed increased, this phenomenon is due to the displacement of the combustion front, since it consumes all the oil and coke that get in contact with the combustion front.

\section{CONCLUSIONS}

The main conclusions for the In Situ Combustion Process after the study of numerical simulation are:

- With the ISC process it was possible to increase the oil recovery factor from the value of the primary production of $16.6 \%$ to $53.26 \%, 46.98 \%$, and $46.99 \%$ for all base cases of Models 1, 2, and 3; respectively.

- One could observe an increase in the oil recovery factor from the value of the primary production of $16.6 \%$ to $71.55 \%, 78.32 \%$, and $78.30 \%$ for the best cases of the Models 1, 2, and 3; respectively.

- After realizing the sensitivity analysis, it was observed that the most influential parameters were the energies of activation pre-exponential factor, followed by the percentage of cracking, and, finally, the flow injection.

- The increase in air injection rate promotes an increase in the oil recovered, but it is observed that there is a limit in the injection of air.

- The breakthrough of air decreased the oil production due to air mobility.

- The chemical reactions models showed a similar behavior in the displacement of the front of oil, however the different kinetic values of chemical reactions make difficult to do comparisons between them.

\section{ACKNOWLEDGEMENTS}

The authors wish to thank the PRH-PB 221 (Petrobras), Computer Modelling Group (CMG), and Laboratory for Advanced Studies in Petroleum (LEAP-UFRN), for the support provided for conducting this work.

\section{REFERENCES}

Adegbesan, K. O. Kinetic Study of Low Temperature Oxidation of Athabasca Bitumen. Ph.D. Thesis, Chemical and Petroleum Engineering, University of Calgary, Alberta, 1982, 229p.

Belgrave, J. D. M.; Moore, M. G.; Ursenbach, D. W. A comprehensive approach to in-situ combustion modelling. SPE Advanced Technology Series, SPE-20250-PA, v. 1(1), p. 98-107, 1993. http://dx.doi.org/10.2118/20250-PA

Burger, J. G.; Sahuquet, B. C. Chemical aspects of in-situ combustion - Heat of combustion and kinetics. Society of Petroleum Engineers Journal, v. 12(5), p. 410-422, 1972.

http://dx.doi.org/10.2118/3599-PA

Chicuta, A. M.; Trevisan, O. V. Experimental study on in-situ combustion of a Brazilian heavy oil. SPE Latin American \& Caribbean Petroleum Engineering Conference, SPE-122036-MS, Cartagena, Colombia, 2009.

http://dx.doi.org/10.2118/122036-ms

Coats, K. H. In-situ combustion model. Society of Petroleum Engineers Journal, SPE-8394-PA, p. 533-554, 1980. http://dx.doi.org/10.2118/8394-PA

Crookston, H. B.; Culham, W. E.; Chen, W. H. A Numerical simulation model for thermal recovery processes. Society of Petroleum Engineers Journal, SPE-6724-PA, v. 19(1), 1979.

http://dx.doi.org/10.2118/6724-PA

Dabbous, M. K.; Fulton, P. F. Low-temperatureoxidation reaction kinetics and effects on the insitu combustion process. Society of Petroleum Engineers Journal, SPE-4143-PA, v. 14(3), p. 253262, 1974. http://dx.doi.org/10.2118/4143-PA

Fassihi, M. R.; Brigham, W. E.; Ramey Jr, H. J. Reaction kinetics of in-situ combustion: Part 1Observations. Society of Petroleum Engineers Journal, SPE-8907-PA, v. 24(4), p. 399-407, 1984. http://dx.doi.org/10.2118/8907-PA

Green, D. W.; Wilhite, G. P. Enhanced oil Recovery. Richardson (Texas): Society of Petroleum Engineers, SPE Textbook Series, v. 6, 1998. 
Lin, C. Y.; Chen, W. H.; Lee S. T.; Culham, W. E. Numerical simulation of combustion tube experiments and the associated kinetics of in-situ combustion processes. Society of Petroleum Engineers Journal, SPE-11074-PA, v. 24(6), p. 657666, 1984. http://dx.doi.org/10.2118/11074-PA

Mamora, D. D. Kinetics of in situ combustion. Ph.D. Thesis, Stanford University, 1993.

Moore, R. G.; Laureshen, C. J.; Ursenbach, M. G.; Mehta, S. A.; Belgrave, J. D. M. Combustion/oxidation behavior of Athabasca oil sands bitumen. SPE Reservoir Evaluation \& Engineering, SPE-59483-PA, v. 2 (6), p. 565-572, 1999. http://dx.doi.org/10.2118/59483-PA

Mothé, C. G.; Silva Jr., C. Petróleo pesado e ultrapesado - Reservas e produção mundial. TN Petróleo, v. 57, p. 76-80, 2008.

Prats, M. Thermal Recovery. Richardson (Texas): Society of Petroleum Engineers, SPE Monograph Series, v. 7, 1982, 283p.

Rojas, J.; Ruiz, J.; Vargas, J. Numerical simulation of an enhanced oil recovery process of Toe to Heel Air Injection (THAI) - Finding the best well pattern. SPE EOR Conference at Oil \& Gas West Asia, SPE129215-MS, p. 1-9, Muscat, Oman, 2010. http://dx.doi.org/10.2118/129215-MS

Rodriguez, J. R. Experimental and analytical study to model temperature profiles and stoichiometry in oxygen-enriched in-situ combustion. Ph.D. Thesis, Texas A\&M University, 2004.
Ruiz, C, P, A. Estudo comparativo da injeção de água usando poços verticais e horizontais. Dissertação de Mestrado, Programa de PósGraduação em Ciência e Engenharia de Petróleo, Universidade Federal do Rio Grande do Norte, 2012. (in Portuguese)

Sarathi, P. In Situ Combustion Handbook Principles and Practices. Oklahoma: National Petroleum Technology Office, U. S. Department of Energy, Report DOE/PC/91008-0374, OSTI ID 3175, 1999.

Schiozer, D. J. Simulación y optimización de yacimientos através de técnicas de computación en paralelo. Información Tecnológica, v. 13(2), p. 183189, 2002.

Tarifa, M. J. Estudo de modelos das reações químicas no processo de combustão in situ. Dissertação de Mestrado, Programa de PósGraduação em Ciência e Engenharia de Petróleo, Universidade Federal do Rio Grande do Norte, 2014, 172p. (in Portuguese) 